\title{
El impacto de la historia oral en la investigación antropológica: un estudio de caso en la Sierra Norte de Puebla
}

The impact of oral history on anthropological research: a case study in the Sierra Norte de Puebla

Iván Deance

Universidad Intercultural del Estado de Puebla, México

Puebla, México

ivan@deance.org.mx

\section{RESUMEN}

La antropología se basa en los métodos y técnicas de investigación etnográfica, los cuales, van desde las entrevistas a profundidad hasta la observación participante. Pese a lo anterior, existen otras herramientas que enriquecen el trabajo antropológico y que provienen de disciplinas diferentes. Este es el caso de la historia oral, sub-disciplina que surge a partir de la recuperación de materiales orales cotejando con fuentes diversas que ayudan a la construcción de un corpus narrativo que contribuye a conocer y comprender el pasado en voz de las personas que lo han vivido. En el presente trabajo se utiliza la historia oral como herramienta para investigación antropológica en el abordaje del conocimiento de la Sierra Norte de Puebla, particularmente en torno a la presa de Necaxa.

Palabras clave: historia oral; antropología; indígenas; náhuatl; tradición oral.

\section{ABSTRACT}

Anthropology is based on ethnographic research methods and techniques, which range from in-depth interviews to participant observation. Despite the above, there are other tools that enrich anthropological work and that come from different disciplines. This is the case of oral history, a subdiscipline that arises from the recovery of oral materials collating with diverse sources that help to build a narrative corpus that helps to know and understand the past in voice of the people who have lived it. In this paper, oral history is used as a tool for anthropological research in the knowledge approach of the Sierra Norte de Puebla, particularly around the Necaxa dam.

Keywords: oral history; anthropology; indigenous; nahuatl; oral tradition. 


\section{INTRODUCCIÓN}

Desde tiempos inmemoriales, la tradición oral ha sido parte fundamental de la reproducción social en cualquier cultura, tomando mayor peso en unas que en otras. Contribuye a conservar historias sobre el origen de las personas, la fundación de los pueblos, anécdotas cotidianas que han trascendido a su tiempo, héroes culturales que le dan sentido a los ideales de cada lugar y mitos que enriquecen la memoria de los pueblos, trayendo consigo momentos lejanos o personas que no están más con nosotros.

Una de las peculiaridades de los métodos de investigación que se impusieron en la segunda mitad del siglo XX es que consideran actores ignorados por la historia tradicional, como las minorías étnicas, campesinos, obreros u otras minorías. Hoy en día, muchas investigaciones se dedican a averiguar la historia de los campesinos, la familia, la mujer como grupo social, la diversidad sexual, la moda, la cocina, etcétera. Estos nuevos campos de estudio provocaron la revaloración de los testimonios y documentos verbales. No es lo mismo escuchar el relato de las dificultades campesinas en las regiones cafeticultoras ante la caída del precio del café, en palabras de quien lo ha vivido, que leer un artículo periodístico sobre este problema.

Debido a lo anterior, prestar mayor atención a los recuerdos, experiencias y puntos de vista de los testigos y actores del acontecer contemporáneo y de la historia reciente se convierte en una obligación, pues en los testigos que no se ven a sí mismos como fuentes históricas, es donde la investigación deberá poner cada vez más su atención y con ello recuperar la vieja práctica de los pueblos originarios, de transmitir la información de padres a hijos, o las costumbres ancestrales de Tucídides y Herodoto al preguntar a la gente lo que vio y lo que conoció. La diferencia es que ahora poseemos medios tecnológicos más avanzados para registrarlo, y tenemos referentes teóricos y conceptuales más ricos que nos ayudan a tratar las fuentes orales con mucha rigurosidad.

Podría recordarse, en particular, una anécdota de Darío. Siendo rey de Persia, llamó a unos griegos presentes en su corte y les preguntó cuánto querían a cambio de comerse los cuerpos de sus padres difuntos. Los griegos replicaron que no existía suficiente dinero en el mundo para pagarles. Después preguntó a unos indios de la tribu llamada callatie, que de verdad comen los cuerpos de sus padres difuntos, cuánto querían para quemarlos (refiriéndose, por su puesto, a la costumbre griega de la cremación). Los indios exclamaron horrorizados que no debía hablarse de cosas tan repugnantes'. (Azcona, 1987, p. 8).

Durante las primeras décadas del siglo XX, se dieron muchos cambios en torno a los fenómenos de estudio de las ciencias sociales y las humanidades. Sobre todo, en el campo de la historia social, se dio un renovado escalafón en la importancia de los sujetos en los sucesos públicos: los heroicos personajes que ganaban batallas y lograban glorias casi por sí solos se quedarían en las versiones oficiales o en la Historia del siglo XIX y sus predecesoras. En adelante, los actores sociales "anónimos" -incluyendo las minorías o los antagonistas-, tomarían una nueva relevancia. Por otra parte, las nuevas tecnologías que permitieron registrar sonidos y voces contribuirían a recabar los relatos orales, que antaño sólo podían ser recabados por escrito, lo cual requería de grandes habilidades en dicho menester o de escribanos profesionalizados en ello, lo que -no sobra advertir- resultaba muy complejo y en no pocas ocasiones carente de confiabilidad.

\footnotetext{
A la historia oral se le puede concebir como una "corriente disciplinar", cuyo campo de influencia y acción no se restringe a un solo país o a un continente, ya que en la actualidad es una práctica de investigación internacional que ha construido sus propias redes y campos de interrelación. Sin embargo, no se identifica con una disciplina en concreto; es decir, la historia, ya que participan una diversidad de estilos y procedencia profesionales. La interdisciplina es uno de sus elementos característicos. (Aceves Lozano, 2006a, p. 10).
}

Otro elemento interesante es que estas nuevas tendencias no sólo contemplaron a los relatos orales, sino que incluyeron otra gama de fuentes que enriquecerían los estudios de los nuevos sujetos protagónicos 
en la historia, lo mismo que la vida cotidiana de ellos y sus comunidades:

Los testimonios de protagonistas más o menos anónimos no fueron las únicas fuentes que comenzaron a tenerse en cuenta. También se incluyeron en esta categoría cartas, diarios íntimos, o fotos familiares, o todo aquello que registrara de alguna manera la vida cotidiana. (Di Marzo, 2005, p. 170)

Vilanova sintetiza así el nuevo reto de la historia oral y su ejecutor:

Para el historiador contemporaneísta, lo más decisivo es establecer un diálogo entre las fuentes escritas, acabadas y limitadas y las fuentes orales abiertas y "vivas", porque unas y otras dan versiones diferentes y, por lo mismo, se potencian y dinamizan entre sí. La palabra hablada ilumina la escrita, revitalizándola y dándole la perspectiva y el contorno humano adecuado. [...] Utilizar honestamente la fuente oral no es fácil, entre otros motivos por el trabajo enorme que supone utilizarla conjuntamente con fuentes escritas. Porque antes de crear la fuente oral debemos recorrer necesariamente un camino previo similar al del trabajo del historiador clásico. Se ha de subrayar este aspecto ya que implica un esfuerzo doble: buscar y analizar las fuentes y, sólo después, crear y analizar las fuentes orales. Las fuentes orales en vez del tiempo largo privilegian el tiempo vivo de la memoria evidenciando hasta qué punto el pasado está presente en las conciencias. [...] Las fuentes orales ayudan a descubrir lo que no ocurrió nunca, aunque se haya escrito una y otra vez y, por ello, son desmitificadoras. Porque a pesar de la escenificación de cualquier diálogo, el testimonio oral es "real", realista, apegado al dato cotidiano y al propio mundo personal. (Thompson, 1988, p. X-XI)

No fue sino hasta finales del siglo XX cuando diversas disciplinas como la literatura, la sociología y la misma antropología, empezaron a interesarse en los testimonios orales, en especial los llamados autobiográficos, sobre todo de personas que no figuraban entre destacados sujetos de la sociedad, sino de ciudadanos comunes o como solemos llamar, la "gente de a pie". Fue entonces cuando surgió una escuela a la que tiempo después se le nombró como historia oral.

La historia es una memoria fabricada según recetas positivistas; un puro discurso intelectual que anula el tiempo mítico (Ronald Barthes, 2007, p. 144). Según, Aceves Lozano, la historia oral en México tiene ya un camino andado, que ha transitado una diversidad de rutas. De hecho, afirma que la historia oral ha sido también un pretexto para la comunicación entre los que la usan y experimentan. Como espacio de comunicación ha sido generosa y ha estado abierta a muchas corrientes y estilos de apropiación. Desde aquéllos que la utilizan puntualmente para cubrir una inquietud específica de su indagación, o los que la usan para complementar y añadir el ingrediente humanista que conlleva este enfoque cualitativo de trabajo; o hasta aquellos que la usan centralmente para la construcción de sus "datos" relevantes de investigación. La intensidad y extensión en su uso es por lo tanto variable y no depende de sí misma, sino de la intención y objetivos de los practicantes de la historia oral. (Aceves Lozano, 2006a, pp. 4-5)

La historia oral que se desarrolló en las últimas dos décadas del siglo XX, ha ofrecido orientación y proporcionado medios para obtener un conjunto de propósitos, como buscar un mejor conocimiento de la historia y la sociedad contemporáneas y de poder contribuir a modificar una práctica científica frecuentemente desligada de su entorno y de los sujetos sociales con que interacciona. (Aceves Lozano, 2006a, p. 9)

Como parte de esta disposición, le ha interesado aportar nuevos cuerpos de evidencias socio históricas, construyendo archivos orales y privilegiando una aproximación cualitativa en el proceso del conocimiento histórico y socio-antropológico. Esta práctica se ha planteado también la conveniencia de propiciar una plataforma para la interacción disciplinaria y llegar a cubrir una función de vínculo entre los actores sociales y los medios de registro, estudio y difusión de aspectos significativos de las experiencias vitales individuales y colectivas. (Aceves Lozano, 2006a, 2006b; de Garay, 2006).

Más la historia oral no es necesariamente un instrumento de cambio; esto depende del espíritu con que 
se lee utilice. En consecuencia, puede usarse para cambiar el enfoque mismo de la Historia y abrir nuevas áreas de investigación; puede romper barreras entre profesores y estudiantes, entre generaciones, entre instituciones docentes y el mundo exterior; y en la escritura de la Historia -sean libros, museos, radio o películas- puede devolver a la gente que hizo y vivió la Historia un lugar central a través de sus propias palabras. (Thompson, 1988, p. 11).

Cabe asimismo señalar que a la historia oral le ha interesado conocer y comprender la dinámica propia de los grupos y sociedades humanas, y, como parte de una disciplina científica, le preocupan los hechos y fenómenos sociales en los que participan instituciones e individuos involucrados en determinados procesos económicos, políticos y culturales. (Aceves Lozano, 2006a, p. 9). Estos intereses de la historia oral surgieron por el esfuerzo de búsqueda de nuevas alternativas para el oficio del historiador, que se fueron concretando en el proceso de detección de "nuevos sujetos sociales", con el propósito de abordarlos en "escalas y niveles locales y regionales", para buscar y comprender fenómenos socio históricos particulares, mediante la producción de "nuevas fuentes" de información y evidencia histórica. Aceves nos indica que la historia oral como método de investigación, orienta y señala, propone y sugiere caminos por ensayar. El autor concluye diciendo que no es un método terminado, porque regularmente se está construyendo en la práctica. (Aceves Lozano, 2006a, pp. 9-10).

El problema para esta investigación radica en la falta de consensos en torno a las historias fundacionales de algunas poblaciones de la región de estudio y la presencia de significados divergentes sobre el nombre de algunas localidades. Dichas significados estas profundamente ligados a las dinámicas sociales, pasadas y presentes, de la vida de dichos pueblos representando su análisis una gran motivación para recurrir a fuentes menos tradicionales en el trabajo de investigación antropológica. Por otra parte, el conocimiento de algunas historias sobre los orígenes de los pueblos y los significados de los nombres de las localidades de la Sierra Norte de Puebla obtenidos en el trabajo de campo de largo aliento en la zona, motivaron el desarrollo de este trabajo.

Es por lo anterior que este texto tiene el objetivo de evidenciar los aportes de la historia oral en la investigación antropológica a partir de un estudio de caso en la Sierra Norte de Puebla, México, en el cual se muestra el uso de las narraciones orales recabadas en entrevistas y trabajo de campo, además de la utilidad que representa el conocimiento sobre las lenguas originarias para el cotejo de los testimonios obtenidos y otros datos sobre el significado de los nombres de algunas poblaciones en la región y las dinámicas sociales que ello representó en el pasado y mantienen significancia en el presente.

\section{MÉTODOS}

Mediante recorridos de investigación en diversas temporadas de campo, así como entrevistas recabadas mediante la observación participante en la Sierra Norte de Puebla, se colectó la información compartida en los apartados posteriores. En sí misma la historia oral representa una orientación metodológica para el levantamiento y usos de la información. En este apartado se mencionan las principales definiciones y concepciones para la recuperación de dichos materiales, su relevancia y su tratamiento a partir de la historia oral.

Se realizaron cinco sesiones de entrevistas a profundidad con María Anita Virginia Salas Domínguez en la Ciudad de México en 2007. Adicionalmente se realizaron cuatro temporadas de campo cortas en la Sierra Norte de Puebla entre 2005 y 2007 y posteriormente se dispuso una estación de campo permanente en la Sierra Norte de Puebla y Sierra de Papantla de 2007 a 2012.

Para poder abordar la historia oral como método, es necesario partir de la materia prima que esta utiliza: la memoria.

Sobre la memoria, Ballesteros nos dice que:

La memoria es un proceso psicológico que sirve para almacenar información codificada. Dicha información puede ser recuperada, unas veces de forma voluntaria y consciente y otras de manera involuntaria. [...] Posiblemente lo más importante para cualquier ser humano es su capacidad 
para almacenar experiencias y poder beneficiarse de dichas experiencias en su actuación futura. El engranaje y los mecanismos que rigen el funcionamiento de este colosal proceso psicológico funcionan con tal grado de perfección que la persona sana apenas es consciente de que todas sus acciones y todas sus comunicaciones verbales dependen del correcto funcionamiento de su memoria. Sin embargo, cuando la memoria falla, ya sea de manera circunstancial y momentánea, ya sea de manera permanente, el individuo se da cuenta, en medio de la frustración, de su importancia. (Ballesteros, 1999, p. 705).

Por su parte Mariezkurrena (2008) menciona que:

La memoria de los informantes no es infalible y ella misma es histórica, el presente matiza el pasado, la selección de los recuerdos existe y generalmente ocultamos más o menos inconscientemente lo que altera la imagen que nos hacemos de nosotros mismos y de nuestro grupo social. Por ello, no hay fuentes orales «falsas». Las afirmaciones equivocadas constituyen verdades psicológicamente ciertas. (Mariezkurrena Iturmendi, 2008, p. 230)

Y continúa diciendo que:

El éxito de una investigación basada en fuentes orales depende de la calidad de las entrevistas que se lleven a cabo, ya que las mismas constituyen la documentación a interpretar por parte del historiador. Una entrevista no es una conversación espontánea, es una situación artificial, donde el entrevistador busca información para su investigación y el entrevistado de alguna manera busca hacer pública su historia y sus puntos de vista. Para llevar a cabo una buena entrevista son necesarios varios requisitos: una adecuada elección de los informantes, un profundo conocimiento previo de la temática a investigar, la definición clara de problemáticas e hipótesis de investigación, la amplitud necesaria para abordar aspectos no contemplados en las instancias previas a la entrevista, que pueden abrir nuevas vertientes, y el registro no sólo de lo dicho sino también de lo omitido. (Mariezkurrena Iturmendi, 2008, p. 231)

Sumado a las definiciones anteriores, cuando pensamos en la memoria y su relación con el pasado, es frecuente que busquemos apelar a la historia y a la reconstrucción de los sucesos que hemos vivido. Al respecto Sarlo nos dice que:

El pasado es siempre conflictivo. A él se refieren, en competencia, la memoria y la historia, porque la historia no siempre puede creerle a la memoria, y la memoria desconfía de una reconstrucción que no ponga en su centro los derechos del recuerdo (derechos de vida, de justicia, de subjetividad). Pensar que podría darse un entendimiento fácil entre estas perspectivas sobre el pasado es un deseo o un lugar común. Más allá de toda decisión pública o privada, más allá de la justicia y de la responsabilidad, hay algo intratable en el pasado. Pueden reprimir sólo la patología psicológica, inintelectual o moral; pero sigue allí, lejano y próximo, acechando el presente como el recuerdo que irrumpe en el momento menos pensado, o como la nube insidiosa que rodea el hecho que no se quiere o no se puede recordar. (Sarlo, 2011, p. 9)

Como se mencionó al comienzo de este apartado, metodológicamente los testimonios y la información recabada fueron construidos a partir de las propuestas de la historia oral:

La historia oral es de gran importancia para reconstruir procesos socio-históricos a partir de la percepción y concepción de los protagonistas, convirtiéndose el testimonio oral en un nuevo documento escrito, pues la entrevista es sistematizada, seccionada con un corpus preplanificado, basado en temas secciones que además es validado por expertos académicos; la historia oral tiene 
como técnica la historia de vida dirigida a especialistas o experimentados en un área de conocimiento determinado, arrojando como resultando nuevos enfoques explicativos, ratificación de ciertos planteamientos científicos y nuevas interpretaciones históricas, sociales y antropológicas. (Lara \& Antúnez, 2014, p. 48)

Al mismo tiempo:

Lo más llamativo de la historia oral o historia de vida, como técnica, es poder trascender como investigadores desde los espacios tradicionales circunscritos a archivos, salas, bibliotecas, e ir a la realidad desde la palabra y con la palabra, adecuándonos simultáneamente con los retos tecnológicos que han superado la grafía y el papel, ubicándonos en la filmación y digitalización del nuevo documento, que puede llegar a todas partes del mundo en cuestión de segundos. (Lara \& Antúnez, 2014, p. 48)

Al respecto es necesario concebir a la historia oral dentro del marco de la historia como disciplina, misma que puede ser entendida en palabras de Carr como sigue:

La historia es, en términos generales, un recuento de lo que han hecho los hombres y adquiere significado y objetividad sólo cuando establece una relación coherente entre el pasado y el futuro [...] Los datos de la historia no pueden ser puramente objetivos, ya que se vuelven datos históricos precisamente en virtud de la importancia que les concede el historiador. La objetividad en la historia -si es que podemos seguir utilizando este vocablo convencional-, no puede ser una objetividad del dato, sino la relación entre dato e interpretación, entre el pasado, el presente y el futuro. [...] La historia llamada así con propiedad sólo puede ser escrita por los que ven y aceptan en la historia misma un sentido de dirección. La convicción de que provenimos de alguna parte está estrechamente vinculada a la creencia de que vamos a algún lado. Una sociedad que ha perdido la fe en su capacidad de progresar en el futuro dejará pronto de ocuparse de su propio progreso en el pasado. [...] Nuestra concepción de la historia refleja nuestra concepción de la sociedad. (Carr, 1999, pp. 184-199)

Sin embargo, no debemos de perder de vista que "una de las características de la historia oral es su naturaleza interdisciplinaria: se abreva de la antropología, de la sociología, de la teoría literaria y de las experiencias realizadas en la educación”. (Hinojosa Luján, 2013, p. 58).

Es así como las voces de otros nos ayudan a construir una nueva historia, que, hasta antes de la consideración de las voces de los ciudadanos comunes contemplados por la historia oral, era inexistente. De esta forma recordamos la afirmación de Barthes que dice que "la historia era una memoria fabricada según recetas positivas, un puro discurso intelectual que anulaba el Tiempo mítico”. (Roland Barthes \& Sala-Sanahuja, 2009, p. 144) y que al contemplar de manera contemporánea los testimonios orales y los aportes de la historia oral, nos permite abordar enfoques interpretativos que insertan con valor social a los mitos y la vida cotidiana en su conjunto. Por su parte, Di Marzo nos dice que "Los testimonios de protagonistas más o menos anónimos no fueron las únicas fuentes que comenzaron a tenerse en cuenta. También se incluyeron en esta categoría cartas, diarios íntimos, o fotos familiares, o todo aquello que registrara de alguna manera la vida cotidiana." (Di Marzo, 2005, p. 170)

El método de la historia oral es utilizado también por muchos estudiosos, sociólogos y antropólogos, sobre todo, que no se consideran como periodistas historiadores orales. (Thompson, 1988, p. 85). Saber escuchar y mirar es parte central de la metodología de la historia oral.

Es necesario indicar que la historia oral contemporánea se ha derivado de una práctica de investigación procedente de una rama de la historia, la "historia social", que a su vez tenía enfoques particulares que promovían acercamientos a la historia contemporánea tratando de abordarla con 
nuevos aportes, tanto por la selección de los sujetos y objetos de la investigación como por los métodos y herramientas a utilizar [...] Por ende, la historia oral puede cumplir entonces un papel de vínculo social, no sólo entre los investigadores y sus sujetos de estudio, sino también entre los que realizan su práctica en este campo de acción disciplinaria. La historia oral la hemos querido concebir como un esfuerzo que suma e integra, y no un proyecto que deslinda y enclaustra. (Aceves Lozano, 2006a, pp. 11-15).

En este momento es pertinente comenzar la distinción que diversos autores. (Collado, 1994; de Garay, 2006; de Garay, 2007; Joutard, 1999; Thompson, 1988), hacen entre "tradición oral" e "historia oral". Las dos provienen de la memoria colectiva pero la primera surge como una necesidad entre las sociedades para transmitir mensajes de generación en generación, los mitos, las leyendas, los cuentos y todo suceso de la comunidad (real o mítico) que forme parte de su autoconciencia y que necesite ser preservado para darle continuidad a la cohesión del grupo. La segunda, mediante la entrevista, busca y construye el testimonio de actores u observadores directos, sobre ciertos aspectos del acontecer que son considerados importantes por el científico social.

\begin{abstract}
Es necesario señalar que existen al menos dos formas de cultivo de la historia oral. La primera busca crear archivos de oralidad, construir fuentes para la consulta de los interesados mediante el depósito en las entrevistas procesadas - de acuerdo con etapas formalmente definidas- en receptáculos adecuados para su conservación. Este tipo de trabajo, que privilegia el procesamiento de archivos de la entrevista, no se interesa en el análisis y la utilización de ésta para una investigación histórica. La segunda, además de abocarse a la recopilación de fuentes orales, acude a la consulta de los mismos testimonios para la elaboración de una investigación determinada. En este caso, el procesamiento y almacenaje de los testimonios no se pega necesariamente a los empleados en la integración de los archivos orales. Sin embargo, a este respecto es necesario llamar la atención de quienes utilizan esta última técnica para que tomen conciencia de que finalmente no sólo están obteniendo materiales para su investigación particular en cuestión, sino que simultáneamente pueden producir fuentes para los investigadores del futuro. Por ello, también la preservación de estos materiales es crucial (Collado, 1994, pp. 14-15).
\end{abstract}

A veces el propósito social de la historia es oscuro. Se conocen historiadores que realizan estudios sobre viejos problemas sociales sorteando cualquier implicación con interpretaciones generales, e insistiendo exclusivamente en la búsqueda del conocimiento por el conocimiento. Aunque esto lo consideramos importante en aras de que la generación de cualquier tipo de conocimiento impulsa la evolución de la humanidad, en el caso del estudio de la historia estos profesionales se abstienen de cuestionar al sistema social. En el otro lado de la balanza "el propósito social de la historia puede ser bastante descarado: la justificación de la guerra y la conquista, las anexiones territoriales, la revolución, y la contrarrevolución, la dominación de una clase o raza sobre otra. Allá donde no se disponga de historia alguna, se la creará (Thompson, 1988, p. 9).

Continuando la línea anterior, es interesante recordar cómo los mismos mexicas vieron la necesidad de construir la "nueva historia", con base en su llegada a la Cuenca del Altiplano Central y plasmar el mito de fundación de Tenochtitlán. Quemaron los códices anteriores y escribieron nuevos. De la misma manera, los ideólogos pos-revolucionarios se apropiaron del mito fundacional mexica para hacer de él un elemento esencial en la construcción del Estado-nación mexicano. 
Imagen 1. La tira de la peregrinación.

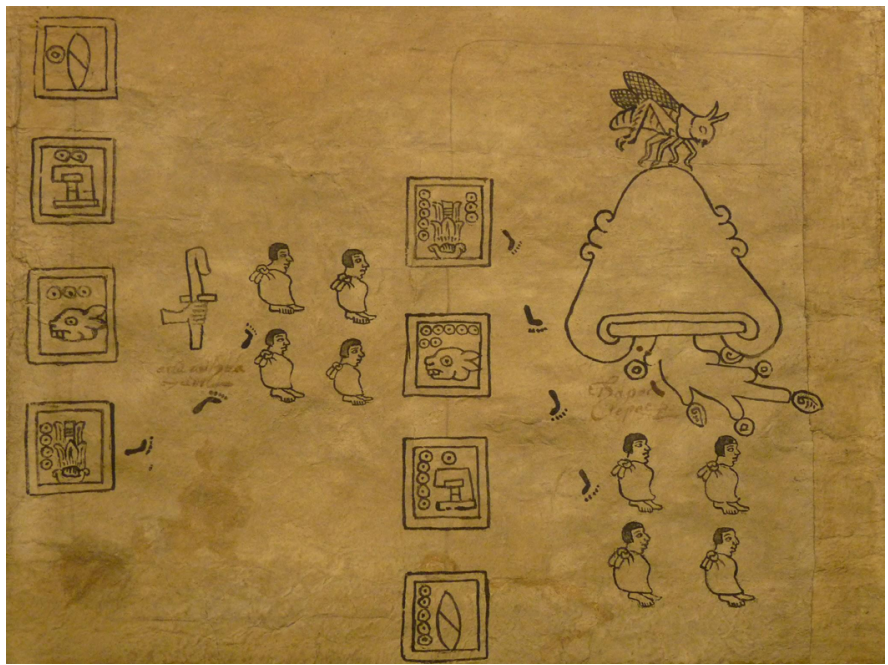

Fuente: Códice Boturini, folio $18^{2}$.

Los mexicas fueron los primeros en "inventar" la "nueva historia” en México, al escribir el códice de La tira de la peregrinación (Johannson, 2007), además de otros documentos; y los ideólogos pos-revolucionarios "reinventaron" o retomaron a los primeros para inventar la nueva "nueva historia". La historia oral pretende, por su parte, evitar que se escriba la historia sólo por los grupos hegemónicos; así, da la voz a aquéllos que jamás hubieran tenido la oportunidad de contar su versión de los hechos. En este sentido Thompson observa:

Hasta el presente siglo, el enfoque de la Historia era esencialmente político [...]. El tiempo histórico se dividía en reinados y dinastías. Incluso la historia local se ocupaba más de la admiración del municipio o la parroquia que de la vida cotidiana de la comunidad. Ello era debido en parte a que los mismos historiadores pertenecían a las clases administrativas y gobernantes [...] No se hallaban interesados por el punto de vista del trabajador, a menos que éste fuese conflictivo, ni -hombres como eran- [se interesaban] por las experiencias innovadoras en la vida de las mujeres. $Y$ aun en el caso de que hubiesen deseado escribir un tipo de Historia diferente, no habría sido fácil puesto que la materia prima de la historia escrita -los documentos- había sido conservada o destruida por personas con las mismas prioridades. Cuanto más personal, local o extraoficial fuese un documento, menos probabilidades tenía de sobrevivir (Thompson, 1988, p. 11).

Y continúa diciendo:

La historia oral [...] hace posible un juicio mucho más equitativo: ahora pueden citarse también testigos de las clases bajas, los desheredados y los derrotados. Lo cual propicia una reconstrucción del pasado más realista y más justa, una alternativa a la interpretación establecida. De este modo la historia oral tiene unas implicaciones radicales para el mensaje social de la Historia en su conjunto (Thompson, 1988, p. 14).

Desgraciadamente, los antropólogos no pueden entrevistar a las tumbas ni a la gente de los panteones, pero al menos, para épocas que van desde la Segunda Guerra Mundial, mediados y finales del siglo XX, el uso de la historia oral suministra inmediatamente una rica y variada fuente al antropólogo creativo. Los antropólogos, apoyados en la historia oral eligen a quién van a entrevistar y los tópicos a abordar. En este proceso se puede igualmente encontrar o propiciar el hallazgo de documentos escritos y fotografías,

2 Se describe el arribo de los mexicas al cerro de Chapultepec en la actual Cuenca del Altiplano Central 
que de otra manera jamás habrían sido identificados. Para el caso de los historiadores más ortodoxos, “los confines del mundo erudito no llegan más allá de los consabidos volúmenes del viejo catálogo. Los historiadores orales pueden ponerse en el lugar del editor: pensar qué evidencia se necesita, buscarla y conseguirla." (Thompson, 1988, p. 13)

Debido a que la historia oral produce testimonios sociales desdeñados por la historiografía ortodoxa, (Collado, 1994, p. 18) es una herramienta metodológica que genera materiales de investigación con aspectos y perspectivas muy distintas, y muchas de éstas no habían sido tratadas o si quiera visibilizadas por la historia tradicional.

Respecto a lo anterior cabe finalizar este apartado con la siguiente cita:

Si la historia se concibe, según Ferratori, como "una memoria colectiva del pasado, conciencia crítica del presente y premisa operativa para el porvenir", estaremos de acuerdo en que la historia oral desempeña un papel preponderante en lo que a la construcción de la historia contemporánea se refiere, debido a que al producirse el testimonio oral los individuos cobran conciencia de su devenir (Collado, 1994, p. 19).

\title{
3. RESULTADOS
}

El texto que sigue, es una reconstrucción de la narración de María Anita Virginia Salas Dominguez a partir de cinco entrevistas a profundidad realizadas sobre su vida. Este texto surge de la temática sobre su natal Necaxa, Municipio de Juan Galindo. Entrevistas realizadas en la Ciudad de México 2007.

\begin{abstract}
El agua le llegaba hasta el cuello, su gélida temperatura le congelaba los huesos y el no tocar el fondo del río le agotaba en extremo. Sus mejillas se hinchaban constantemente al tratar de retener la mayor cantidad de aire posible, los cabellos mojados le tapaban los ojos como si fueran las ramas de un sauce y los dedos de sus pies eran una masa de piel y huesos casi insensible, el pequeño titiritaba de frío, pataleaba y se impulsaba con los brazos de manera ineficiente pero no podía hacer otra cosa que nadar por su vida. No muy delante de él, una persona de mediana edad luchaba por escapar, tras de él, algunos cadáveres flotaban inertes cual ramas trozadas por algún ventarrón sobre las aguas de aquel profundo río, otras personas más luchaban incesantemente por cruzar y sobrevivir. Gritos de pavor y sollozos de desesperanza inundaban el ambiente, una madre en lontananza nadaba sola, acompañada solo por la sombra de la muerte; aquellos que no lograban convivir con la crueldad de la corriente, saciaban la sed de venganza de aquellos perseguidores que miraban a sus presas perecer, irónicamente, entre el elemento del cual depende la vida. La sensación de no poder más, de estar al límite de fallecer, de tener la nariz llena de agua y tragarla sin cesar, eran horrores tan grandes que más de uno pensó en cortar su agonía entregándose a la muerte o entregando a los suyos de una manera salvaje pero breve.

Una serie de tosidos secos de larga duración, propiciados por la abuela Virginia, rompieron el hilo del relato sobre aquel legendario escape; sus mejillas se sonrojaron y sus ojos se inundaron de lágrimas. El aire le faltó unos instantes y su temblorosa mano tuvo que recurrir a la borla de madera sobre el descansabrazos de su vieja mecedora. Cuando regresó de su espasmo, dejó en claro su intención de no continuar la narración; tomó un poco de aire, limpió las lágrimas en sus ojos y luego de peinar sus cejas concluyó: “y así fue como los toltecas atravesaron por aquel histórico lugar y gracias a eso le llamaron, Patoltecoya, que quiere decir en mexicano 'paso de los toltecas'. (Entrevista, María Anita Virginia Salas Dominguez)
\end{abstract}

Agotada por la emoción de la historia y dejándola inconclusa al no poder hablar más, se reposó nuevamente en la mecedora que le daba tanto placer y mirando a través del mosquitero de alambre en la gran ventana de su habitación, hizo crujir la duela sobre la que se mecía para descansar y recordar aquellos días en los que ella escuchaba, junto con sus hermanos, las intensas historias que durante las tardes de invierno se hicieran presentes, en la dulce voz de su madre.

La abuela Virginia gustaba de contar muchas historias sobre su pueblo natal y la región que le vio nacer. 
Sin embargo, aun cuando Patoltecoya se encuentra a un costado de la presa de Necaxa donde ella nació, antes de la década de 1900 este pueblo se ubicaba más al sur en la ribera del río Totolapa.

Con la construcción del sistema hidroeléctrico, tanto Necaxa como Patoltecoya fueron reubicados y los asentamientos originales quedaron inundados, por lo que el seguimiento de dicha "historia" presentaba grandes saltos temporales y una enorme dificultad para ubicarla cronológicamente y asociarla con los toltecas. La versión del llamado "paso de los toltecas" es tan popular en la región como el topónimo de Necaxa al que suele atribuirse el significado de "habitantes del cajete de agua" o "aquí me descalzo", ya que, de acuerdo con esta versión, las personas tenían que quitarse lo que trajeran calzando para poder cruzar el río.

Ninguna de estas versiones, aceptadas popularmente, están sustentadas de manera sólida, ni por la tradición oral, ni por la documental. Por ello se asume su error etimológico y se identifica poca claridad en ambos topónimos. Al respecto, dos autores señalan que al nombre de Patoltecoya se le han dado varios significados, pero uno de los más disparatados es la interpretación que hizo don Sandalio Mejía en su ya anacrónico libro "Huauchinango Histórico" (Garrido Cruz, 2009, p. 1). El desaparecido cronista dijo que el nombre derivaba de ipan tolteco, oyan frase sin sentido gramatical náhuatl, pero que don Sandalio quiso interpretar como "Lugar por donde pasaron los toltecas". Asombra que muchos sigan aceptando esta errada etimología (Garrido Cruz \& Tino Antonio, 2010, p. 5).

\section{Imagen 2- Glifo de Toltecoyan. Lienzo “B” de Acaxochitlán}

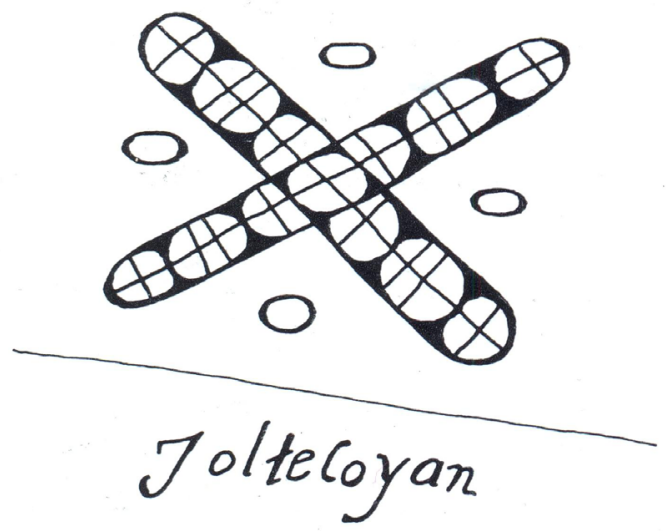

Fuente (Stresser-Pean, 1998, p. 157-158)3.

La historia oral y la etnohistoria le han dado un nuevo significado a aquel afamado lugar y la interpretación más adecuada para dicho topónimo es "Lugar donde se juega el patolli" debido a los elementos que lo conforman: "patolli”, juego prehispánico, "co" locativo y el sufijo locativo "yan” el cual expresa acción.

El patolli es un juego prehispánico de azar practicado en un tablero en forma de cruz trazado con hule derretido sobre un petate. Este juego fue registrado por cronistas y aparece en algunos códices como en el caso de los Lienzos de Acaxochitlán (Stresser-Péan, 1998, pp. 130, 144, 153, 158. Lienzo B), en el Códice Magliabecchi (Westheim, 2000, p. 210. lámina 48) y en el Códice Florentino (de Sahagún, 1979, p. Libro 8, f.19r). Por su parte, los Lienzos de Acaxochitlán (Stresser-Péan, 1998, p. 144) nos muestra el tablero de cruz propio del patolli en el glifo de dicha población con el nombre al pie, aunque sin la primera sílaba; es decir, "Toltecoyan" (Stresser-Péan, 1998, pp. 152,158). En este caso la respuesta apareció en cuanto se revisó el códice mencionado, reafirmando las anteriores hipótesis de los filólogos nahuas. 


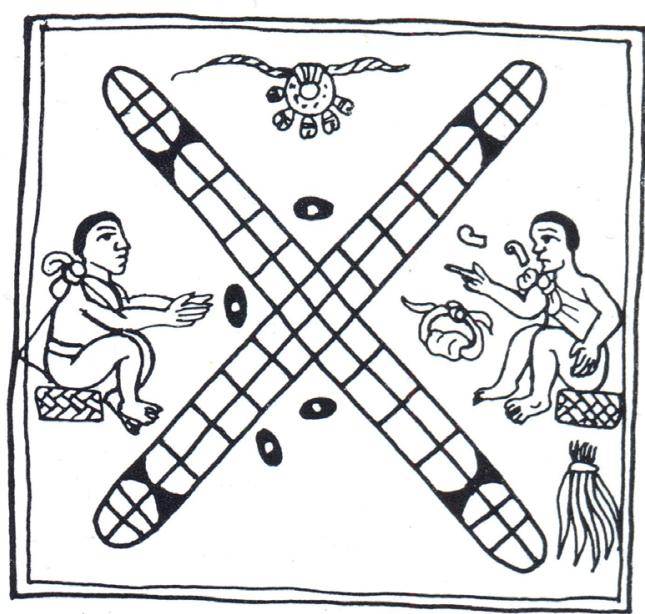

Fuente: Códice Florentino, libro 8, f.19r. ${ }^{4}$

En cuanto al significado de Necaxa, el problema se complica al no tener presencia clara en los códices que describen la región, ni en las crónicas de viajeros y visitadores. Sin embargo, la importancia de la vitalidad de las lenguas indígenas en la región da la respuesta a dicha cuestión.

Como ya se mencionó, el asentamiento original en Necaxa tuvo que trasladarse por la obras de la presa. Pero está documentado tanto por los ingenieros ingleses a través de imágenes como por la memoria de los habitantes, que existía una gran caída de agua, la cual fue aprovechada para la generación de electricidad en los modernos dínamos del sistema hidroeléctrico, hace más de un siglo. Los habitantes mestizos no recuerdan dicha cascada, más el registro de su existencia quedó en los archivos de la recién extinta Compañía de Luz y Fuerza del Centro.

Imagen 4. Panorámica del río Necaxa y el pueblo de Patoltecoya en tiempo de sequía 2011.

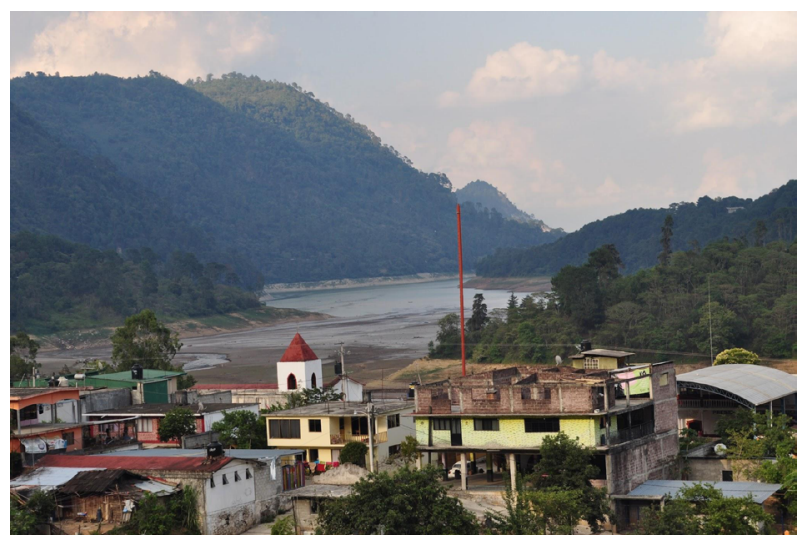

Fuente: Fondo Deance-Vázquez, 20110615vvv-09.

4 "Alfonso Caso (1925) descubrió que el juego de patolli ha sobrevivido bajo una forma degenerada y aberrante en la Sierra Norte del Estado de Puebla, donde todavía lo practican, a $20 \mathrm{~km}$ al sur de Patoltecoyan, los nahuas de Huitzilán y los de Xochitlán, así como los totonacos de Zapotitlán, Hueytlalpan, Olintla y Bienvenido". (Stresser-Pean, 1998, pp. 160). 
Antes de la construcción de las presas, la caída de agua era majestuosa tanto por su caudal como por el estruendo del golpe con que el agua azotaba en el fondo del río, y es precisamente esto lo que los habitantes indígenas de las regiones vecinas registraron en su lengua y en su memoria histórica. Si bien en Necaxa se habló náhuatl hasta hace algunas décadas, hoy el pueblo se encuentra amestizado y sólo conserva el recuerdo de su pasado indígena gracias a una localidad subalterna llamada Necaxaltepetl, en donde aún hoy día se habla dicha lengua, aunque el significado de Necaxa se haya perdido en el tiempo. El poblado reubicado luego de la construcción de la presa fue llamado Nuevo Necaxa y el municipio del cual es cabecera se llama Juan Galindo, en honor a un militar de filiación liberal que luchó en contra de los conservadores y se destacó en la batalla de Tecacalango, en la que los franceses a cuyo frente iba el Conde de Cinco Iglesias fueron derrotados. Galindo comandó un ataque con piedras que desbarrancaron de lo alto de un cerro, aplastándolos a su paso. Pese a los cambios de ubicación y a los cambios del nombre de Necaxa, los otomíes y los totonacos conservaron el término con el que se designaba a su pueblo vecino antes de la gran obra hidráulica. Dichos términos resultan muy interesantes, pues la palabra ruido está presente en el topónimo y se presentan en la siguiente tabla:

Tabla 1. Términos para referirse al pueblo de Necaxa desde las lenguas originarias de la región

\begin{tabular}{|l|l|l|}
\hline Náhuatl & Otomí & Totonaco \\
\hline Necaxa & Magëhë & Ka'ksaan \\
\hline desconocido & ma-gë-hë & ka'-ksaan \\
\hline desconocido & (locativo)-ruje-profundo & (locativo)-ruido \\
\hline desconocido & “Lugar del rugido en la profundidad” & “Lugar de ruido” \\
\hline
\end{tabular}

Fuente: Información recabada en 2005 por el Dr. Guillermo Garrido Cruz (Historiador y lingüista hablante de náhuatl, corroborada en 2007).

Es importante mencionar que en los topónimos de la región que existen desde diferentes lenguas, varios tienden a coincidir a partir de los términos descriptivos según Garrido Cruz y Tino Antonio. ${ }^{5}$ Debido a esto es muy probable que Necaxa significase en otro tiempo "el ruido que hacía el agua al caer" o algo similar, y no "en el cajete"; al igual que en el topónimo Patoltecoya, en cuya interpretación se buscó un significado homófono con sentido parcial en idioma castellano.

\section{DISCUSIÓN Y CONCLUSIONES}

Los ejemplos anteriores de reconstrucción de topónimos ${ }^{6}$ a partir de fuentes no consideradas tradicionalmente por la antropología, obligan a reflexionar en torno a la pertinencia del uso de la tradición oral como fuente de investigación y herramienta antropológica, la cual se tambalea entre los mitos y realidades pasadas, dificultando como investigadores, asir la historia no documental de una manera clara, como si la historia documental lo fuera. Por su parte, la etnohistoria abre fuentes diversas que toman en cuenta a aquellas personas y sus colectivos, sobre todo a aquellos que no han tenido la opción del registro escrito para plasmar su continuidad en el devenir de los años. Pero el trabajo con estas fuentes es mucho más delicado de lo que pareciera, y puede llevar las investigaciones por caminos muy obscuros y difíciles de atravesar exitosamente.

Trabajar con la tradición oral y los relatos orales en general, dándoles coherencia, cadencia y legitimidad para poder construir la historia oral, no es fácil. Pese a esto es un reto tan maravilloso como el reconstruir una ciudad que quedó en escombros luego de una guerra o un desastre natural. Para dicho trabajo, cada investigador o investigadora, no sólo se basa en las descripciones de los sujetos de la región, sino en muchas otras fuentes que le ayuden a obtener el mejor resultado posible. Aun así, la construcción de una historia oral para explicar los fenómenos de estudio, es fundamental.

\footnotetext{
5 Comunicación personal del Dr. Guillermo Garrido y del Dr. Jorge Tino Antonio (Historiador y Lingüista hablante de totonaco).

6 Los topónimos son los nombres propios de un lugar determinado. "Representan un valor cultural intangible que puede ser centro de interés educativo para dar a conocer y respetar el patrimonio, promover el diálogo intercultural y asegurar la sustentabilidad de los territorios." (Luigi de Requena et al., 2015)
} 
Se sabe que es mucho más común dejar los relatos orales a los literatos y a los estudiosos del folclor, pero hoy existe una corriente madura que ha posicionado a la historia oral como una disciplina sólida. Dar un lugar en la construcción histórica a lo que la gente sabe, cree que sabe y lo que cree que no sabe a partir de los relatos orales, es una de las tareas de la antropóloga y el antropólogo contemporáneo.

Si bien Amezcua (2015) nos recuerda que los testimonio orales podrían ser tomados como elementos históricos subjetivos pues son individualistas, frágiles y cambiantes, debido a que se apoyan en la memoria, que está en constante revaloración, es necesario recordar que toda experiencia, recordada por escrito o de forma oral en un dato subjetivo en sí mismo y para el individuo representan una verdad. Independientemente que lo registrado en la entrevista pueda ser cotejado como una verdad o no, lo realmente importante de los datos recabados radica en la experiencia del sujeto y su interpretación, ya sea objetiva o subjetiva, debido a que, por su perfil cultural y su historia de vida única, sus aportes siempre nos reflejarán la perspectiva de una época y una generación.

De modo que, al hablar de la historia oral como un método de investigación, se refiere al procedimiento establecido de construcción de nuevas fuentes para la investigación socio histórica y, en nuestro caso, para la investigación antropológica con base en los testimonios orales recogidos sistemáticamente para investigaciones específicas, bajo métodos, problemas y puntos de partida teóricos, explícitos. Con la tecnología más avanzada el antropólogo actual rescata al personaje más antiguo de la historia oral: al "contador de historias", responsable de construir las identidades de los pueblos.

Hacer historia oral significa, por lo mismo, producir conocimientos históricos, científicos y no simplemente lograr una exposición ordenada de fragmentos y experiencias de vida de los "otros". El historiador oral es más que la grabadora que amplifica las voces de los individuos "sin historia", ya que procura que la evidencia oral no sustituya a la labor propia de investigación ni al análisis socio histórico; que su papel como investigador no quede reducido a ser sólo un eficiente entrevistador, que su esfuerzo y capacidad de análisis científico no queden depositados y sustituidos por la cintas de grabación. No sólo le importa construir y sistematizar sus nuevas "fuentes orales", sino que requiere integrarlas y confrontarlas con los demás acervos históricos (Aceves Lozano, 2006a, pp. 10-12).

Sin embargo, el presente trabajo presenta algunas limitaciones basadas en la dependencia de las entrevistas orales. Es necesario recurrir al cotejo de más fuentes documentales además de los códices citados. Es sumamente probable que en los archivos parroquiales y archivos municipales se pueda encontrar información que enriquezca este y otros trabajos basados en testimonios orales e información recabada en el trabajo campo. Aquí es donde queda un largo camino por recorrer por lo que continuar con estas vetas de investigación abre la oportunidad a nuevas posibilidades de investigación sobre la Sierra Norte de Puebla.

Cuando surge en la Sierra Norte de Puebla la plática entre los habitantes de la región, o inclusive en los discursos y la documentación oficial, sobre los significados de los topónimos de Patoltecoya y Necaxa, la incredulidad y la deslegitimación sobre los significados de la palabra Necaxa referidos anteriormente a partir de la historia oral en las glosas mostradas en otomí y totonaco o en el significado del náhuatl sobre Patoltecoya a partir de las referencias de los códices y la glosa en náhuatl mostrada, impiden el diálogo y la reflexión sobre los topónimos en la región, la población prefiere mantener la idea generalizada de los significados de "paso de los toltecas" para Patoltecoya y "en el cajete de agua" para Necaxa. Inclusive la abuela Virginia se negaba a aceptar dichas conjeturas. Respecto a la comprensión de los sucesos descritos en su historia, se puede inferir que sus interpretaciones están en gran medida influenciados por sus referentes aprendidos en la educación formal, su aprendizaje familiar, así como las relaciones con las personas que le vieron crecer. No obstante, siempre existen más alternativas para reconstruir el pasado y cuyas opciones no sólo se reducen a lo aprendido de manera formal, informal o a lo que "todo el mundo sabe", sino a la colecta de datos e información que incluyen los mitos, las historias de los viejos, los cuentos y todo el conjunto de elementos que la memoria colectiva pueda guardar y preservar. Sin embargo, hay que tomarlos con las debidas reservas y no cómo verdades o dogmas. Es responsabilidad de cada investigador e investigadora cotejar los elementos recabados para la construcción de la historia oral con la mayor diversidad de fuentes adicionales posibles para la comprensión de los fenómenos de estudio.

Como ya se mencionó, el relato con el que comienza este apartado es una narración que describe un suceso que se supone pasó en realidad, dada su presencia en diferentes lugares. Es sin embargo poco probable 
que fueran las familias toltecas de hace cientos de años, las protagonistas de aquel suceso, porque de acuerdo con nuestro seguimiento a partir de la tradición oral, así como de algunas fuentes documentales, dicho suceso podría corresponder más a una familia perseguida por una deuda política que les hizo dejar la región en la primera mitad del siglo XX. Lo curioso es que la abuela Virginia prefería creer que fueron "sus antepasados milenarios" los que huyeron, antes que aceptar que fue una familia "reciente", como la suya, la que tuvo que abandonar la hermosa Sierra Norte al perder una contienda política como la perdiera su padre, cuya familia fue perseguida y obligada a abandonar el pueblo de Necaxa pasando por Huauchinango y Beristain, antes de llegar a la ciudad de México hace más de 70 años.

Durante el ejercicio antropológico en la Sierra Nororiental y Sierra Norte de Puebla, quien escribe, pudo aprender en una medida funcional, el totonaco o mejor dicho una de las lenguas totonacanas de la región. En ese tenor, el aprendizaje de dicha lengua permitió al equipo de investigación, conocer y desarrollar conocimiento sobre elementos de aplicación tecnológica y herramientas matemáticas a partir del totonaco (Deance, 2017) que rebasaron por mucho las expectativas de "sólo acercarse a elementos de la tradición y la vida cotidiana". Sin embargo, en la construcción de la historia oral se encontró conocimiento de otros pueblos, de otras regiones y de otros tiempos. La construcción de la historia oral y la recuperación de la oralidad sobre diversos tópicos desde la lengua originaria, como en el caso antes expuesto de los topónimos recabados por Guillermo Garrido, los cuales permitieron en este trabajo, reconocer diversas historias que con sólo el trabajo etnográfico eran difíciles de corroborar.

Al final, la construcción de la historia oral, basada a su vez en la tradición oral, historias de vida y otras fuentes no tradicionales de la historia, no hace sino enriquecer el trabajo antropológico; lo nutre, lo complementa y sin desplazarlo, contribuye al mejor entendimiento de la diversidad sociocultural en México, el resto de Latinoamérica y el mundo.

Los parientes entrevistados platican que cuando la abuela Virginia era ya muy vieja, le bañaron y le peinaron hasta su muerte. También comentaron que cuando la mamá de la abuela Virginia era muy vieja, también le bañaron y le peinaron hasta su muerte y añadieron que cuando sus nietos visitaban a la mamá de la abuela Virginia y le llevaba mameyes dulces y besos amargos mientras la peinaban, ella les pagaba con historias de su natal Huahuchinango y de su esposo proveniente de Pantepec, historias que por tantos años se olvidaron hasta que el presente trabajo permitió a los parientes la reflexión de la memoria en el proceso de la construcción de la historia oral y sus aportes al ejercicio antropológico, luego de revisar algunas grabaciones que se le hicieron a la abuela Virginia antes de que dejara de hablar y que motivaron a la realización de este texto.

Los parientes mencionados de la abuela Virginia emigraron desde la sierra a diferentes lugares donde habitan hoy o murieron hace algunos años. Y sucedió que sus abuelos se conocieron y también sus padres; así sucedió que conocieron a sus parejas y algunos tuvieron hijos. Lo importante ante esta relación de parentesco y emigración de la Sierra, es que las historias que ellos no reflexionaron hasta este proyecto de investigación, fueron reveladas y serán enseñadas a sus hijos y los hijos de sus hijos, todo gracias a que la abuela Virginia así lo hizo. Por lo anterior, el presente trabajo defiende que la historia oral puede ayudar a mejorar el ejercicio contemporáneo de la antropología en México, igual que las abuelas ayudan a mejorar el entendimiento de lo que son las familias y de dónde vienen, sólo con contar sus historias a sus descendientes.

\section{REFERENCIAS}

Aceves Lozano, J. E. (2006a). Historia Oral. Ensayos y aportes de la investigación. Seminario de Historia Oral y Enfoque Biográfico (2a ed.). Centro de Investigaciones y Estudios Superiores en Antropología Social.

Aceves Lozano, J. E. (2006b). Sobre los problemas y métodos de la historia oral. En G. De Garay, La historia con micrófono: Textos introductorios a la historia oral. Instituto Mora.

Amezcua, M. (2015). Memoria e Historia oral: La voz como documento. Fundación INDEX.

Azcona, J. (1987). Para comprender la antropología: Vol. tomo I. Editorial Verbo Divino.

Ballesteros, S. (1999). Memoria humana: Investigación y teoría. Psicothema, 11(4), 705-723. http://www.psicothema. com/psicothema.asp?id=323

Barthes, R., \& Sala-Sanahuja, J. (2009). La cámara lúcida: Nota sobre la fotografía. Paidós. 
Barthes, Ronald. (2007). La cámara lúcida. Notas sobre la fotografía. Paidós.

Carr, E. H. (1999). ¿Qué es la historia? Ariel.

Collado, C. (1994). ¿Qué es la historia oral? En G. De Garay, La historia con micrófono: Textos introductorios a la historia oral. Instituto de Investigaciones Dr. José Ma. Luis Mora.

De Garay, G. (2006). La historia con micrófono: Textos introductorios a la historia oral. Instituto de Investigaciones Dr. José Ma. Luis Mora.

De Garay, G. (2007). Para Pensar el Tiempo Presente: Aproximaciones Teórico-Metodológicas y Experiencias Empíricas. Instituto de Investigaciones Dr. José Ma. Luis Mora.

De Sahagún, F. B. (1979). Códice Florentino. AGN.

Deance, I. (2007). Entrevistas a profundidad con María Anita Virginia Salas Dominguez en la Ciudad de México. Grabación sonora y en video: 22" 12'. MAVSD2007-1.

Deance, I. (2007). Entrevistas a profundidad con María Anita Virginia Salas Dominguez en la Ciudad de México. Grabación sonora: 1:15" 03’. MAVSD2007-2.

Deance, I. (2007). Entrevistas a profundidad con María Anita Virginia Salas Dominguez en la Ciudad de México. Grabación en video: 17" o0'. MAVSD2007-3.

Deance, I. (2007). Entrevistas a profundidad con María Anita Virginia Salas Dominguez en la Ciudad de México. Grabación sonora: 1:40"02'. MAVSD2007-4.

Deance, I. (2007). Entrevistas a profundidad con María Anita Virginia Salas Dominguez en la Ciudad de México. Grabación sonora: 55". MAVSD2007-5.

Deance, I. (2017). Totooffice: Experiencias interculturales en torno a la lengua y la tecnología. En, M. García y F. Maniglio (Eds). Los territorios discursivos en América Latina: Interculturalidad Comunicación e Identidad. (pp. 98-115). Ediciones CIESPAL, SoLEI.

Di Marzo, L. C. (2005). Una araña en el zapato. En G. Pompillo (Comp.) Una araña en el zapato. Libros de la Araucaria. Garrido Cruz, G. (2009, julio 18). La toponimia regional. Radio Expresión: La información sin límites | Noticias.

Garrido Cruz, G., \& Tino Antonio, J. (2010). El estudio de la toponimia como fuente para la historia del Totonacapan. [Congreso]. 1er coloquio de historia social: Investigación, fuentes y enseñanza, Benemérita Universidad Autónoma de Puebla, Puebla, México.

Hinojosa Luján, R. (2013). La historia oral y sus aportaciones a la investigación educativa. revista de investigación educativa de la Rediech, 3(5), 57-65. https://doi.org/10.33010/ie_rie_rediech.v3i5.562

Johannson, P. (2007). Tira de la Peregrinación: Códice Boturini; La saga del pueblo mexica, de Aztlán a la Cuenca de México. (Vol. 26). Instituto Nacional de Antropología e Historia.

Joutard, P. (1999). Esas Voces Que Nos Llegan Del Pasado. Fondo de Cultura Económica.

Lara, P., \& Antúnez, Á. (2014). La historia oral como alternativa metodológica para las ciencias sociales. Revista de Teoría y Didáctica de las Ciencias Sociales, 20, 45-62. http://www.saber.ula.ve/handle/123456789/42540

Luigi de Requena, M., Aranguren, J., \& Moncada, J. A. (2015). La toponimia como elemento educativo ambiental y patrimonial en el Monumento Natural Cerro María Lionza. Revista de Investigación, 39(84), 205-226. http:// ve.scielo.org/scielo.php?pid=S1010-29142015000100010\&script=sci_abstract

Mariezkurrena Iturmendi, D. (2008). La historia oral como método de investigación histórica. Gerónimo de Uztariz, 23-24, 227-233. https://dialnet.unirioja.es/servlet/articulo?codigo=3264024

Sarlo, B. (2011). Tiempo pasado: Cultura de la memoria y giro subjetivo; una discusión (1. ed., 1. reimpresión). Siglo XXI

Stresser-Péan, G. (1998). Los Lienzos de Acaxochitlán (Hidalgo) y su importancia en la historia del Poblamiento de la Sierra Norte de Puebla y zonas vecinas (1a.). Centro de Estudios Mexicanos y Centroamericanos, Gobierno del Estado de Hidalgo, Consejo Estatal para la Cultura y las Artes de Hidalgo.

Thompson, P. (1988). La voz del pasado. Historia oral. Edicions Alfons el Magnànim, Institució Valenciana D’estudis i Investigació.

Westheim, P. (2000). Obras maestras del México Antiguo. Siglo XXI. 


\section{AUTOR}

Iván Deance. Doctor en Historia y Etnohistoria y Licenciado en Etnología, Maestro en Estudios Regionales, Posdoctorados en Historia y Antropología, Diplomados en Lingüística descriptiva y empatía cultural y en Peritaje en Ciencias Antropológicas, miembro del Sistema Nacional de Investigadores del Consejo Nacional de Ciencia y Tecnología, del Colegio de Etnólogos y Antropólogos Sociales, de la Asociación Internacional de Historia Oral y de la Asociación Universal de Esperanto. Líder del cuerpo académico consolidado “Imagen, Memoria e Investigación Social" y posee la certificación del Programa Internacional de Alta Capacitación: Internacionalización, Liderazgo y Comunicación por la Next International Business School.

\section{Conflicto de intereses}

El autor declara tener ningún conflicto de interés.

\section{Financiamiento}

No existió asistencia financiera de partes externas al presente artículo.

\section{Agradecimientos}

$\mathrm{N} / \mathrm{A}$ 